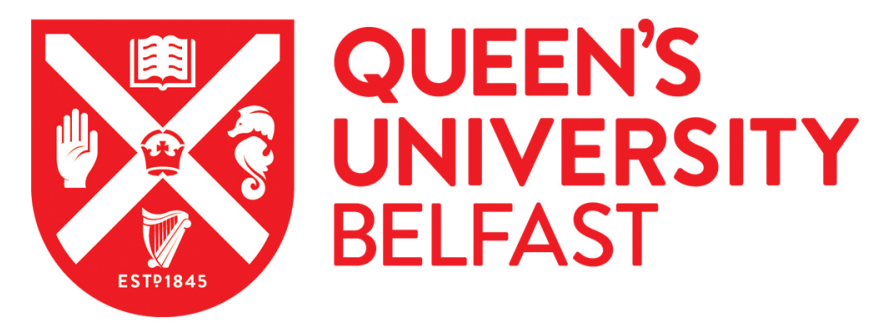

\title{
Anticipated delay in help-seeking for cancer symptoms: Findings from a nationwide study of Malaysian adults
}

Schliemann, D., Ismail, R., Donnelly, M., \& Su, T. T. (2021). Anticipated delay in help-seeking for cancer symptoms: Findings from a nationwide study of Malaysian adults. Cancer Epidemiology, 71(101882). https://doi.org/10.1016/j.canep.2020.101882

Published in:

Cancer Epidemiology

Document Version:

Peer reviewed version

Queen's University Belfast - Research Portal:

Link to publication record in Queen's University Belfast Research Portal

\section{General rights}

Copyright for the publications made accessible via the Queen's University Belfast Research Portal is retained by the author(s) and / or other copyright owners and it is a condition of accessing these publications that users recognise and abide by the legal requirements associated with these rights.

Take down policy

The Research Portal is Queen's institutional repository that provides access to Queen's research output. Every effort has been made to ensure that content in the Research Portal does not infringe any person's rights, or applicable UK laws. If you discover content in the Research Portal that you believe breaches copyright or violates any law, please contact openaccess@qub.ac.uk. 
Title: Anticipated delay in help-seeking for cancer symptoms: findings from a nationwide study of Malaysian adults

Running title: Anticipated delayed help-seeking for cancer symptoms in Malaysia

Authors*: Désirée Schliemann ${ }^{1}$, Roshidi Ismail ${ }^{2,3}$, Michael Donnelly ${ }^{1}$, Tin Tin $\mathrm{Su}^{2,3}$

*Désirée Schliemann and Roshidi Ismail contributed equally to this paper.

\section{Affiliations:}

${ }^{1}$ Centre for Public Health and UKCRC Centre of Excellence for Public Health, Queen's University Belfast, Belfast, UK

${ }^{2}$ South East Asia Community Observatory (SEACO) \& Global Public Health, Jeffrey Cheah School of Medicine and Health Sciences, Monash University Malaysia

${ }^{3}$ Centre for Population Health (CePH), Department of Social and Preventive Medicine, Faculty of Medicine, University of Malaya

Corresponding author: Tin Tin Su / TinTinSu@monash.edu

\section{ORCID ID:}

Désirée Schliemann: 0000-0002-8746-3002

Tin Tin Su: 0000-0003-0387-6406 


\begin{abstract}
Background: To investigate the relationship between anticipated delay in help-seeking and cancer symptom recognition and the extent to which this relationship varied according to socio-demographic and health-related characteristics.
\end{abstract}

Methods: A cross-sectional telephone survey was conducted of 1,895 adults aged $\geq 40$ years who were randomly selected across Malaysia and interviewed using the validated Awareness and Beliefs about Cancer questionnaire. Logistic regression analysis was used to test the associations between anticipated delay for help seeking $>2$ weeks and socio-demographic and health-related variables.

Results: Delay in help-seeking was reported for persistent cough (19.3\%), rectal bleeding (6.1\%) and breast changes (2.5\%). Difficulty in accessing a doctor was associated with delayed help-seeking for breast changes and rectal bleeding (adjusted ORs 7.58; 95\% CI 1.98, 28.94 and 2.37; 95\% CI 1.21, 4.66, respectively); not recognising symptoms as a cancer warning sign was associated with delayed help-seeking for rectal bleeding (adjusted OR 1.54; 95\% CI 1.03, 2.31); and ethnicity was associated with anticipated delay for rectal bleeding and persistent cough.

Conclusions: Generally, anticipated delay to help seeking for cancer symptoms in Malaysia (a middle income country) appeared to be a less significant problem compared to other countries including high income countries. There appeared to be a significant association between social variation indicators in Malaysia and anticipated delay in help seeking.

Key words: anticipated delay, help-seeking, cancer, Malaysia, LMIC 


\section{Introduction}

Early detection of cancer is of paramount importance to improve chances of survival [1,2]. In Malaysia, breast, colorectal and lung cancer are the most common cancers (ASR 34.1/100,000, 25.9/100,00 and $19.1 / 100,000$ respectively) [3]. About $50 \%$ of breast cancer cases, over $70 \%$ of colorectal cancer cases and over $90 \%$ of lung cancer cases are diagnosed at stage 3 or 4 ; and contribute to increasing cancer mortality (9,466 in 2012 vs 11,966 in 2016) [3]. In addition, there were 5,257 non-medically certified cancer deaths in 2012 and 6,731 in 2016. The Ministry of Health recommends opportunistic screening for both breast and colorectal cancer for $\geq 50$ year olds - there is no organised population-based cancer screening and screening of the asymptomatic at-risk population is minimal [4,5]. Limited population cancer screening statistics and studies suggest that $4 \%$ of the eligible population receive breast cancer screening [6] and $<1 \%$ attend colorectal cancer screening [7]. At-risk populations need to be aware of common cancer symptoms, recognise their potential severity and seek medical help. Results from the few studies about the awareness of common cancer signs and symptoms in Malaysia are inconsistent. We have reported nation-wide awareness levels for the following cancer symptoms: 'lump' - 74.5\%, rectal bleeding $-65.5 \%$ and 'persistent cough' - 55.4\% [8] whereas other (albeit smaller) studies reported proportions ranging from $28 \%$ to $91 \%$ for awareness of lump as a breast cancer symptom [911 ] and between $34 \%$ and $72 \%$ for rectal bleeding as a colorectal cancer sign [12-14]. Awareness about lung cancer symptoms is largely unexplored [15]. Similarly, the association between specific cancer symptom awareness and socio-demographic factors and symptom awareness and the intention to seek help in Malaysia have been under investigated.

The time it takes to seek help is often referred to as 'delayed help-seeking' [16-18], although there is an argument for using terms such as 'time to presentation' or 'prolonged help-seeking' that have no negative connotation [19]. From here on, we use 'delayed help-seeking' to refer to the concept of prolonged time to seeking medical help after noticing a potential cancer symptom. Several qualitative studies describe psychosocial reasons for delayed help-seeking for breast cancer symptoms in Malaysia such as the negative influence of relatives, financial concerns, fatalistic beliefs about cancer and denial of the disease [20,21]. Nationwide, population-based research is sparse that investigates the association between socio-demographic variables and awareness of symptoms for different cancers in order to contribute to the identification at-risk groups for late presentation. Findings from the international benchmarking partnership survey suggested that people with better symptom awareness were $5-10 \%$ less likely to delay medical help-seeking [16]. The main objective of this research was to assess the association between breast, colorectal and lung cancer symptom recognition and anticipated delay in help-seeking in a nationwide population sample of Malaysian adults using an internationally validated measurement tool, the Awareness and Beliefs about Cancer (ABC) questionnaire [22]. Furthermore, we wanted to assess the relationship between symptom recognition and delay in help-seeking (for a key symptom related to breast, colorectal and lung cancer) with socio-demographic and health-related 
characteristics. Symptom appraisal models or theories [23], principally the Model of Pathways to Treatment [24], was used to help conceptualise and plan the analysis. In brief, the study aimed to improve understanding about the factors that are associated with (i) cancer awareness among the Malaysian population and (ii) intention to seek help for given cancer symptoms.

\section{Methods}

A cross-sectional, nationwide telephone survey assessed cancer awareness and beliefs in line with the approach that has been used in the International Cancer Benchmarking Study; thereby enabling comparisons between Malaysia and higher income countries like UK and Canada [22,25]. The survey was conducted March-November 2014.

\section{Study Setting and Population}

The three main ethnic groups are Malays (69\%), Chinese (23\%) and Indians (7\%) [26]. Participants were selected randomly to represent people living across Malaysia who met the inclusion criteria: able to understand and speak Melayu, Mandarin, Tamil or English, had a mobile phone number and were aged $\geq 40$ years. Cancer incidence is increasing particularly for people aged 40 years and above (i.e. males ASR 35-39 y.: 1,454/100,000; 40-44 y.: 2,135/100,000 and females ASR 35-39 у.: 3,388/100,000; 40-44 у.: 5,089/100,000) [3].

\section{Sampling}

Mobile phone numbers were purchased by the research team from a company providing telephone numbers for research purposes. In total, 150,000 phone numbers were generated randomly taking into account operator prefixes. A sample of 55,000 phone numbers were retained after inactive numbers were removed, of which 10,000 numbers were randomly selected for the first calls. Two thousand of those numbers were allocated to each of five calling stations. It was not practicable to assess the eligibility of every holder of a phone number. Trained research assistants called 8,406 active phone numbers of which 4,913 phone calls were answered, 3,254 numbers belonged to people who met the inclusion criteria and 1,895/3,254 (58\%) participants agreed to participate.

\section{Measurement tool}

The $\mathrm{ABC}$ questionnaire tool was previously validated and culturally adapted (i.e. through contextual translation and cognitive interviews to check respondents understanding) used to assess awareness and 
beliefs about 11 different cancer symptoms. This study focused on awareness about three out of the 11 cancer symptoms, i.e. 'persistent cough or hoarseness', 'unexplained bleeding' and 'unexplained lump or swelling' [22] as indicators of the three most prevalent cancers in Malaysia (lung, colorectal and breast cancer). Participants were asked 'I'm now going to list some symptoms that may or may not be warning signs for cancer. For each one, can you tell me whether you think that it could be a warning sign for cancer?' Participants were asked how long it would take them to go to a doctor from the first time they noticed a persistent cough, rectal bleeding or breast changes (as a way of assessing delay). The cancer awareness-assessed symptoms (i.e. persistent cough or hoarseness, unexplained bleeding and unexplained lump/swelling) varied slightly from the symptoms that were posed in the assessment of anticipated delay in help-seeking (i.e. persistent cough, rectal bleeding and breast changes), though symptoms in both assessments referred to lung, colorectal and breast cancer, respectively. Women, only, were asked about help-seeking for breast changes. The ABC survey included questions about socio-demographic and health care information.

\section{Interviews}

Telephone interviews were conducted by trained research staff with language skills in English, Melayu, Mandarin and/or Tamil. Respondents who agreed to participate were interviewed on first contact or appointments were arranged whenever respondents were busy or if a interviewer in the preferred language was unavailable. Telephone 'stations' comprised computer-assisted telephone interview (CATI) software (www.surveysystem.com/interviewing-cati.htm) with an uploaded ABC questionnaire.

\section{Statistical analysis}

Data entered in CATI was read automatically into an Excel spreadsheet which was transferred into Stata SE. Chi-square analyses examined univariate relationships between sociodemographic characteristics and $>2$ weeks anticipated delayed help-seeking for persistent cough, rectal bleeding and breast changes; and symptom recognition (persistent cough and hoarseness, unexplained bleeding and unexplained lump or swelling). Multivariable logistic regressions tested associations between anticipated delay and socio-demographic characteristics, i.e., sex, age, ethnicity, education, marital status as well as access to a doctor and recognition of the relevant symptom. We also performed a joint test (testparm) to test associations between variables with more than two categories and delayed help-seeking. No weights were applied to account for the sampling distribution. The $>2$ week interval that was employed in the analysis is the delay duration that is employed usually and its use facilitated comparisons with other studies $[16,18]$. 


\section{Results}

The survey was completed by 1,895 participants across Malaysia. The distribution of participants across the 13 states and three federal territories is shown in Supplementary Table 2. More males (57.1\%) than females participated and the majority of participants were married (87.8\%), ethnically Malay (48.8\%) and Chinese (39.8\%), completed secondary (55.5\%) and tertiary education (34.5\%) and reported that they had easy access to a doctor (95.8\%). The mean age of the study population was 48.1 (SD 7.8, range $40-86)$ years and the majority was aged between $40-49$ years $(67.5 \%)$.

Most participants were aware that an unexplained lump or swelling could be a sign of cancer $(74.5 \%)$, followed by unexplained bleeding (65.5\%) and a persistent cough (55.4\%) (Table 1). Females appeared to have better awareness than males about unexplained bleeding $(68.3 \%$ vs $63.5 \%, \mathrm{p}=0.031)$ and an unexplained lump or swelling $(77.0 \%$ vs $72.6 \%, \mathrm{p}=0.031)$ as potential cancer signs. Participants aged $\geq 60$ years were least likely to be aware of any of the three symptoms. There were significant betweenethnic group differences in awareness about each symptom. In particular, the 'other' ethnic group category had the lowest recognition rates for unexplained bleeding and unexplained lump or swelling as a sign of cancer. The association between ethnic groups and symptom knowledge was not as apparent after the 'other' ethnic group was removed from the analysis. Participants without formal education were less likely to recognise any of the three symptoms compared to participants with formal education. Married participants were more likely to identify persistent cough or hoarseness as a cancer sign compared to non-married participants $(56.6 \%$ vs $46.8 \%$ respectively, $\mathrm{p}=0.005)$. The number of participants who reported that they had difficulty accessing a doctor was small $(n=80)$, however, those who did, were less likely to recognise unexplained bleeding as a cancer sign compared to participants with easy access $(50.0 \%$ vs $66.2 \%$ respectively, $\mathrm{p}=0.003)$.

A minority of participants anticipated a delay in help-seeking of $>2$ weeks after noticing these symptoms (Table 2), particularly for breast changes (2.5\%) and rectal bleeding (6.1\%). However, almost $20 \%$ of participants reported that they would delay help-seeking for a persistent cough. There were significant ethnic group differences regarding anticipated delay in help-seeking of $>2$ weeks for the symptoms of persistent cough $(\mathrm{p}=0.004)$. Chinese were most likely to delay help-seeking $(23.3 \%)$ and 'others' were least likely (13.5\%). Ethnic group differences also persisted between ethnic groups for delay in help-seeking of $>2$ weeks for rectal bleeding $(\mathrm{p}=0.004)$. A higher proportion of Malays were likely to delay help-seeking for rectal bleeding (8.0\%) compared to Indians (2.5\%). A higher proportion of participants without formal education reported an anticipated delay in help-seeking for rectal bleeding and breast changes compared to participants who completed formal education (Table 2). More participants who reported that they experienced difficulty accessing a doctor also reported an anticipated delay in help-seeking for rectal bleeding and breast changes compared to participants with easy access ( $17.3 \%$ vs $5.6 \%, \mathrm{p}<0.001$ and $14.8 \%$ vs $2.1 \%$, p $<0.001$, respectively). 
Figure 1 shows small differences in anticipated delay in help-seeking for $>2$ weeks between participants who were aware and unaware of respective symptoms. Participants who were unaware that rectal bleeding was a sign of cancer were more likely to delay help-seeking for $>2$ weeks $(8.6 \%$ vs $4.8 \%$, $\mathrm{p}=0.001$ ). There were no significant differences in delayed-help-seeking and symptom awareness for the other two symptoms, i.e. between respondents who were unaware that breast lump/swelling were a sign for breast cancer $(1.6 \%$ vs yes $2.8 \% ; \mathrm{p}=0.395)$ and between respondents who were unaware that a persistent cough was a sign for lung cancer $(20.4 \%$ vs yes $18.4 \%$; $\mathrm{p}=0.289)$, respectively.

The logistic regression confirmed that ethnicity, education, access to a doctor and symptom recognition were associated with delayed help-seeking $>2$ weeks for some cancer symptoms (Table 3). Findings were similar in the unadjusted analysis (Supplementary Table 3). Chinese were more likely to delay help-seeking $>2$ weeks for persistent cough compared to Malays (adjusted OR 1.58, 95\% CI 1.23, 2.03, $\mathrm{p}<0.001)$ and, both Chinese and Indians, were less likely to delay help-seeking $>2$ weeks for rectal bleeding compared to Malays (adjusted OR 0.58, 95\% CI 0.37, 0.89, $\mathrm{p}=0.014$ and adjusted OR 0.33, $95 \%$ CI $0.12,0.93, \mathrm{p}=0.036$, respectively). Participants with no formal education were significantly more likely to delay help-seeking for $>2$ weeks for the symptom, rectal bleeding compared to respondents with tertiary education (adjusted OR 5.25, 95\% CI 1.86, 14.83, $\mathrm{p}=0.002$ ). There was a weak association between symptom recognition and anticipated delay in help-seeking $>2$ weeks for the symptom rectal bleeding (adjusted OR 1.54, 95\% CI 1.03, 2.31, $\mathrm{p}=0.036$ ). Participants without formal education were around five times more likely to delay help-seeking for rectal bleeding compared to respondents with tertiary education (adjusted OR 5.25, 95\% CI 1.86, 14.83, $\mathrm{p}=0.002$ ) and respondents who were unaware that rectal bleeding was a symptom of cancer were more likely to delay help-seeking compared to respondents who were aware of the cancer symptom (adjusted OR 1.54, 95\% CI 1.03, 2.31, $\mathrm{p}=0.036$ ). Difficulties accessing a doctor was associated with delayed help-seeking $>2$ weeks for rectal bleeding (adjusted OR 2.37, 95\% CI 1.21, 4.66, $\mathrm{p}=0.012$ ) and breast changes (adjusted OR 7.58, $95 \%$ CI 1.98, 28.94, $\mathrm{p}=0.003$ ).Joint testing of the association between delayed help-seeking and variables with more than two categories confirmed that findings presented here. It also suggested that education was associated with a delay in help-seeking for breast changes (Supplementary Table 2).

\section{Discussion}

This was the first conducted nationwide study in Malaysia that investigated the association between cancer symptom awareness and anticipated delayed help-seeking for three different cancers. Participants who recognised the cancer symptoms of unexplained bleeding and unexplained lumps tended to view them as severe symptoms that required medical attention. Only a small number of participants indicated that they anticipated a delay in help-seeking if they experienced breast changes $(2.5 \%)$ or rectal bleeding $(6 \%)$ though $19.3 \%$ reported that they would wait for $>2$ weeks to seek medical 
help for a persistent cough which was also the least recognised cancer symptom. Major public health programmes present a persistent cough as a key sign in lung cancer awareness-raising campaigns. A 'persistent cough' may be a symptom of other illnesses including minor illnesses or chronic illnesses such as asthma that participants may perceive as less urgent. These findings differ to a certain extent from findings from the International Cancer Benchmarking Study (ICBS) [16] where participants overall anticipated a longer delay to help-seeking ( $8.2 \%, 7.2 \%$ and $48.1 \%$ vs $2.5 \%, 6.1 \%$ and $19.3 \%)$. Findings from the ICBS also suggested that not recognising a symptom as a potential cancer sign was associated with an anticipated delay in help-seeking for all three symptoms; and a meta-analysis of studies from 22 different countries, which concluded that better symptom knowledge (OR $=0.73,95 \%$ CI $0.63,0.84)$ and more positive beliefs about cancer $(\mathrm{OR}=0.70,95 \%$ CI $0.52,0.92)$ were associated with lower odds of a delay in help-seeking in healthy adult populations, universally [17]. Most studies were from the UK and other high-income countries. Low- and middle-income (LMICs) countries were represented, however, studies in LMICs where conducted mainly with patient- rather than healthypopulations. Findings suggested that higher income (inequality) was related to stronger protective effects in relation to cancer symptom knowledge [17]. The weak relationship between respondents with higher vs lower symptom awareness in the findings presented here may be due, partly, to the small number of participants who reported anticipated delayed help-seeking for $>2$ weeks for breast and colorectal cancer symptoms. This is the first nation-wide study to report anticipated delay to helpseeking in Malaysia and further research is required to confirm (or otherwise) the findings. The findings presented here may not be reflective of the general population. The anticipated prompt help-seeking in Malaysia compared to elsewhere may be related to differences between healthcare systems. For example, waiting times to see a doctor in England can be over two weeks [27], whereas there does not appear to be waiting, or to be only brief waiting, times in Malaysia and private and public primary care clinics appear to be accessible to patients and to be used regularly by the general population [28]. It is important to keep in mind when interpreting the results that the symptoms that were used to assess breast and colorectal cancer awareness were similar but they varied slightly from the symptoms that were used to assess perceived time to help-seeking. Each symptom tends to be targeted in national public health programmes as a key sign of a major cancer (breast and CRC respectively) and as a prompt to seek medical consultation but the formulation and presentation of the symptoms in relation to helpseeking in the present study may have been interpreted by respondents as relating to conditions other than cancer and to conditions that might not be deemed unusual or requiring urgent medical attention. $[29,30]$

Income was not assessed as part of this study. However, a lack of formal education and difficulties accessing a doctor appeared to be predictors of anticipated delay, which may point to the need to give greater attention to the potential impact of social disparities in Malaysia. A cross-sectional study in Perak, one of the states in Malaysia, suggested that participants with limited education and a low income 
were more likely to anticipate a delay in help-seeking for colorectal cancer symptoms [31]. Furthermore, particular symptoms appeared to have more salience for specific ethnic groups, and ethnicity in relation to certain symptoms appeared to exert a differential influence on anticipated delay in help-seeking. The results did not differ significantly when different time intervals (1- and 4-week time cut-off points) were entered into the regression analysis and history of smoking did not confound the associations described between demographic variables and delayed help-seeking for a persistent cough (not presented here due to space limits but available on request).

It is likely that, in addition to socio-demographic factors, other psycho-social factors (that have not been assessed in this study) are important in terms of explaining anticipated delayed help-seeking. According to a systematic review of qualitative studies, 'symptom awareness', 'symptom interpretation' and 'symptom monitoring' were the most important themes in the help-seeking process for women with breast cancer symptoms [32]. This review and a second qualitative review [33] together concur with our results in terms of pointing to the importance of perceived inaccessibility of health services, particularly regarding breast changes and rectal bleeding. The second qualitative review [33] also found that lack of symptom awareness delayed presentation for lung cancer. Additional reported themes were social interactions and emotional reactions [32]. Findings from a large cross-sectional study in England that looked at diagnostic audits, reported that certain symptoms are diagnosed at an earlier stage and argued that most common cancer symptoms need to be promoted [34]. The findings reported here indicate that symptom recognition is only one (early) step in the help-seeking pathway [35]. A crosssectional study of colorectal cancer patients in Malaysia suggested that about $60 \%$ of patients who experienced rectal bleeding delayed help-seeking and, therefore, other barriers beyond awareness may prevent prompt help-seeking when faced with the symptoms [36]. Factors such as access to health care and education also play a part in the decision to initiate help-seeking. Barriers such as financial concerns, lack of information online, perceived poor quality of care, negative influence of relatives, being too busy, fear and embarrassment appear to merit attention in terms of improving understanding about anticipated time to help-seeking for cancer [37-39].

\section{Study strengths and limitations}

Major strengths of this study include the fact that residents from all states in Malaysia were captured in the survey, the use of the validated $\mathrm{ABC}$ measurement tool and, therefore, the facility to make direct comparisons with international studies. Several potential methodical limitations need to be considered when interpreting the findings. It is important to bear in mind that the study was not powered to detect differences or associations whilst controlling for all covariates. Arguably, the way in which the validated $\mathrm{ABC}$ questionnaire assesses symptom awareness for 'unexplained lump or swelling' and 'unexplained bleeding' and the relationship with delayed help-seeking is not directly comparable to the 
way it enquires about 'breast changes' and 'rectal bleeding'. Although the relevant ABC items appear to represent expressions of similar symptoms, it is unclear whether it is valid to assume that awareness about 'unexplained bleeding' as a potential sign of cancer would prompt timely help-seeking for 'rectal bleeding'. Furthermore, Chinese participants and males appeared to be overrepresented in the sample (Chinese $39.8 \%$ vs $23 \%$ and males $57.1 \%$ vs $51.6 \%$ according to population estimates) [26], and about $90 \%$ of participants completed either secondary or tertiary education (compared to $60 \%$ in the 2010 census [40]) and over 95\% reported easy access to a doctor. The results suggest that there is a need to find alternative ways in which to reach those sections of the population with a low level of education and poor access to health-care.

\section{Conclusion}

There is a need to improve anticipated time to help-seeking for potential cancer symptoms among particular sections of the population in Malaysia, namely, people who are disadvantaged in terms of income and education. In this study, knowledge about cancer symptoms, help-seeking behaviour, sociodemographic factors and perceived easy access and/or structural factors to health care appear to explain variation in delay regarding the time of patient presentation and, subsequently, the detection and diagnosis of cancer in Malaysia. It is important to be mindful when interpreting the results and drawing conclusions about how subtle differences between the presentations of symptoms in questions relating to awareness compared to help-seeking may have affected responses. Nonetheless, the results appear to suggest that there is a need to give consideration to the development and investigation of multi-level interventions that are sensitive to the social needs of members of particular population groups and communities and that address symptom awareness as well as help-seeking behaviour [41]; and for public health efforts that aim to reduce help-seeking delay to take account of the differences that appear to persist for particular communities [42].

\section{Ethical approval}

Ethical approval was granted by the University of Malaya Medical Centre Ethics Committee (Reference Number 890.6). The review board approved the provision of verbal consent as informed consent. Consent to participate was given verbally and the participants could withdraw consent freely at any time during the interview.

\section{Acknowledgements}

The authors would like to acknowledge the help of Associate Professor Nabilla Al Sadat and remember with respect and gratitude the contribution from Prof Liam Murray (RIP) during the early stages of the UM-QUB collaboration. 
Conflict of interest

None.

Data availability

Data is available on request from the corresponding author Prof Tin Tin Su.

\section{Funding}

This research was supported by the University of Malaya: Vice Chancellor's special funding. The funder had no role in the design of the study, collection, analysis, and interpretation of data or writing the manuscript. MD and DS were part funded by the Medical Research Council UK - Newton Fund (MR/P013910/1) and the MRC UKRI GCRF (MR/S014349/1) during the analysis and writing of this paper. 


\section{References}

[1] B.A. Magaji, F.M. Moy, A.C. Roslani, C.W. Law, Survival rates and predictors of survival among colorectal cancer patients in a Malaysian tertiary hospital, BMC Cancer. 17 (2017) 1-8. https://doi.org/10.1186/s12885-017-3336-z.

[2] Office for National Statistics, Cancer survival in England: national estimates for patients followed up to $2018,(2019)$.

https://www.ons.gov.uk/peoplepopulationandcommunity/healthandsocialcare/conditionsanddis eases/bulletins/cancersurvivalinengland/stageatdiagnosisandchildhoodpatientsfollowedupto201 8.

[3] Ministry of Health Malaysia, Malaysia National Cancer Registry Report 2012-2016, Putrajaya, 2020.

[4] Ministry of Health Malaysia, Clinical Practice Guidelines Management of Colorectal Cancer Malaysia, Putrajaya, 2017.

[5] Ministry of Health Malaysia, Clinical Practice Guidelines Management of Breast Cancer Malaysia 2010, Putrajaya, 2010.

[6] A. Mahmud, S.M. Aljunid, The uptake of mammogram screening in Malaysia and its associated factors: A systematic review, Med. J. Malaysia. 73 (2018) 202-211.

[7] Ministry of Health Malaysia, Personal communication, (2019).

[8] D. Schliemann, R. Ismail, M. Donnelly, C.R. Cardwell, T.T. Su, Cancer symptom and risk factor awareness in Malaysia: findings from a nationwide cross-sectional study, BMC Public Health. (2020).

[9] D. Schliemann, M.N.N. Htay, M. Dahlui, D. Paramasivam, C.R. Cardwell, N.S.B. Ibrahim Tamin, S. Somasundaram, C. Donnelly, T.T. Su, M. Donnelly, The impact of a mass media campaign on breast cancer symptom awareness and screening uptake in Malaysia: findings from a quasi-experimental study, BMJ Open. (2020).

[10] M. Abdul Hadi, M.A. Hassali, A.A. Shafie, A. Awaisu, Knowledge and perception of breast cancer among women of various ethnic groups in the state of penang: A cross-sectional survey, Med. Princ. Pract. 19 (2010) 61-67. https://doi.org/10.1159/000252837.

[11] M. Dahlui, D. Eng, H. Gan, N.A. Taib, R. Pritam, J. Lim, Predictors of Breast Cancer Screening Uptake : A Pre Intervention Community Survey in Malaysia, Asian Pacific J. Cancer Prev. 13 (2012) 3443-3449.

[12] T.T. Su, J.Y. Goh, J. Tan, A.R. Muhaimah, Y. Pigeneswaren, N.S. Khairun, A.W. 
Normazidah, D.K. Tharisini, H.A. Majid, Level of colorectal cancer awareness: a cross sectional exploratory study among multi-ethnic rural population in Malaysia., BMC Cancer. 13 (2013) 376. https://doi.org/10.1186/1471-2407-13-376.

[13] D. Schliemann, D. Paramasivam, M. Dahlui, C.R. Cardwell, S. Somasundaram, N.S.B. Ibrahim Tamin, C. Donnelly, T.T. Su, M. Donnelly, Change in public awareness of colorectal symtpoms following the Be Cancer Alert Campaign in the multi-ethnic population of Malaysia, BMC Cancer. (2020).

[14] M.Y. Harmy, D. Norwati, N.M. Noor, A. R. Amry, Knowledge and attitude of colorectal cancer screening among moderate risk patients in West Malaysia., Asian Pac. J. Cancer Prev. 12 (2011) 1957-60. http://www.ncbi.nlm.nih.gov/pubmed/22292632.

[15] K.C. Siang, C.K.M. John, A review of lung cancer research in Malaysia, Med. J. Malaysia. 71 (2016) 70-78.

[16] S.L. Quaife, L.J.L. Forbes, A.J. Ramirez, K.E. Brain, C. Donnelly, A.E. Simon, J. Wardle, Recognition of cancer warning signs and anticipated delay in help-seeking in a population sample of adults in the UK, Br. J. Cancer. 110 (2014) 12-18. https://doi.org/10.1038/bjc.2013.684.

[17] D. Petrova, Y. Okan, E. Salamanca-Fernandez, S. Dominguez-Lopez, M.J. Sanchez, Psychological factors related to time to help-seeking for cancer symptoms: a meta-analysis across cancer sites, Health Psychol. Rev. (2018). https://www-tandfonlinecom.queens.ezp1.qub.ac.uk/doi/full/10.1080/17437199.2019.1641425.

[18] K.A. Rendle, E.A. Sarma, S.L. Quaife, K.D. Blake, R.P. Moser, J.M. Suls, H.M. Edwards, S.C. Kobrin, Cancer Symptom Recognition and Anticipated Delays in Seeking Care Among U.S. Adults, Am. J. Prev. Med. 57 (2019) e1-e9. https://doi.org/10.1016/j.amepre.2019.02.021.

[19] D. Weller, P. Vedsted, G. Rubin, F.M. Walter, J. Emery, S. Scott, C. Campbell, R.S. Andersen, W. Hamilton, F. Olesen, P. Rose, S. Nafees, E. Van Rijswijk, S. Hiom, C. Muth, M. Beyer, R.D. Neal, The Aarhus statement: Improving design and reporting of studies on early cancer diagnosis, Br. J. Cancer. 106 (2012) 1262-1267. https://doi.org/10.1038/bjc.2012.68.

[20] J.N.W. Lim, B. Potrata, L. Simonella, C.W.Q. Ng, T.C. Aw, M. Dahlui, M. Hartman, R. Mazlan, N.A. Taib, Barriers to early presentation of self-discovered breast cancer in Singapore and Malaysia: A qualitative multicentre study, BMJ Open. 5 (2015) 1-9. https://doi.org/10.1136/bmjopen-2015-009863.

[21] N.A. Taib, C.H. Yip, W.Y. Low, A grounded explanation of why women present with 
advanced breast cancer, World J. Surg. 38 (2014) 1676-1684. https://doi.org/10.1007/s00268013-2339-4.

[22] A.E. Simon, L.J.L. Forbes, D. Boniface, F. Warburton, K.E. Brain, A. Dessaix, M. Donnelly, K. Haynes, L. Hvidberg, M. Lagerlund, L. Petermann, C. Tishelman, P. Vedsted, M.N. Vigmostad, J. Wardle, A.J. Ramirez, An international measure of awareness and beliefs about cancer: development and testing of the ABC, BMJ Open. 2 (2012) e001758. https://doi.org/10.1136/bmjopen-2012-001758.

[23] K.L. Whitaker, S.E. Scott, J. Wardle, Applying symptom appraisal models to understand sociodemographic differences in responses to possible cancer symptoms: A research agenda, Br. J. Cancer. 112 (2015) S27-S34. https://doi.org/10.1038/bjc.2015.39.

[24] S.E. Scott, F.M. Walter, A. Webster, S. Sutton, J. Emery, The model of pathways to treatment: Conceptualization and integration with existing theory, Br. J. Health Psychol. 18 (2013) 4565. https://doi.org/10.1111/j.2044-8287.2012.02077.x.

[25] L.J.L. Forbes, A.E. Simon, F. Warburton, D. Boniface, K.E. Brain, A. Dessaix, C. Donnelly, K. Haynes, L. Hvidberg, M. Lagerlund, G. Lockwood, C. Tishelman, P. Vedsted, M.N. Vigmostad, A.J. Ramirez, J. Wardle, C. Benchmarking, P. Module, W. Group, Differences in cancer awareness and beliefs between Australia, Canada, Denmark, Norway, Sweden and the UK (the International Cancer Benchmarking Partnership): do they contribute to differences in cancer survival?, Br. J. Cancer. 108 (2013) 292-300. https://doi.org/10.1038/bjc.2012.542.

[26] Department of Statistics Malaysia, Current Population Estimates, Malaysia, 2017-2018, (2018).

https://www.dosm.gov.my/v1/index.php?r=column/cthemeByCat\&cat=155\&bul_id=c1pqTnFj b29HSnNYNUpiTmNWZHArdz09\&menu_id=L0pheU43NWJwRWVSZk1WdzQ4TlhUUT09 (accessed January 28, 2019).

[27] J. Wise, Many patients in England are waiting mor than two weeks to see a GP, figures show, BMJ. (2018) 363:k5221.

[28] S. Jaafar, K. Mohd Noh, K.A. Muttalib, N.H. Othman, J. Healy, K. Maskon, A.R. Abdullah, J. Zainuddin, A.A. Bakar, S.S.A. Rahman, F. Ismail, Y.Y. Chew, N. Baba, Z.M. Said, Malaysia Health System Review., Health Syst. Transit. 3 (2013) 1-103. http://www.wpro.who.int/asia_pacific_observatory/hits/series/Malaysia_Health_Systems_Revi ew2013.pdf.

[29] A.F. Pedersen, L. Forbes, K. Brain, L. Hvidberg, C.N. Wulff, M. Lagerlund, S. Hajdarevic, S.L. Quaife, P. Vedsted, Negative cancer beliefs, recognition of cancer symptoms and 
anticipated time to help-seeking: An international cancer benchmarking partnership (ICBP) study, BMC Cancer. 18 (2018) 1-10. https://doi.org/10.1186/s12885-018-4287-8.

[30] M. O’Mahony, G. McCarthy, P. Corcoran, J. Hegarty, Shedding light on women's help seeking behaviour for self discovered breast symptoms, Eur. J. Oncol. Nurs. 17 (2013) 632639. https://doi.org/10.1016/j.ejon.2013.03.012.

[31] K.W. Loh, H.A. Majid, M. Dahlui, A.C. Roslani, T.T. Su, Sociodemographic predictors of recall and recognition of colorectal cancer symptoms and anticipated delay in help- seeking in a multiethnic Asian population., Asian Pac. J. Cancer Prev. 14 (2013) 3799-804. https://doi.org/10.7314/APJCP.2013.14.6.3799.

[32] Z. Khakbazan, A. Taghipour, R.L. Roudsari, E. Mohammadi, Help seeking behavior of women with self-discovered breast cancer symptoms: A meta-ethnographic synthesis of patient delay, PLoS One. 9 (2014) 1-24. https://doi.org/10.1371/journal.pone.0110262.

[33] S. Cassim, L. Chepulis, R. Keenan, J. Kidd, M. Firth, R. Lawrenson, Patient and carer perceived barriers to early presentation and diagnosis of lung cancer: A systematic review 11 Medical and Health Sciences 1117 Public Health and Health Services 11 Medical and Health Sciences 1112 Oncology and Carcinogenesis, BMC Cancer. 19 (2019) 1-14. https://doi.org/10.1186/s12885-018-5169-9.

[34] M.M. Koo, R. Swann, S. Mcphail, G.A. Abel, L. Elliss-brookes, G.P. Rubin, G. Lyratzopoulos, Presenting symptoms of cancer and stage at diagnosis: evidence from a crosssectional, population-based study, Lancet Oncol. 2045 (2019) 1-7. https://doi.org/10.1016/S1470-2045(19)30595-9.

[35] B.L. Andersen, J.T. Cacioppo, D.C. Roberts, Delay in seeking a cancer diagnosis: Delay stages and psychophysiological comparison processes, Br. J. Soc. Psychol. 34 (1995) 33-52.

[36] S.M. Hashim, T.S. Fah, K. Omar, M.R.A. Rashid, S.A. Shah, I. Sagap, Knowledge of colorectal cancer among patients presenting with rectal bleeding and its association with delay in seeking medical advice, Asian Pacific J. Cancer Prev. 12 (2011) 2007-2011.

[37] J.N. Lim, B. Potrata, L. Simonella, C.W. Ng, T.-C. Aw, M. Dahlui, M. Hartman, R. Mazlan, N.A. Taib, Barriers to early presentation of self-discovered breast cancer in Singapore and Malaysia: a qualitative multicentre study., BMJ Open. 5 (2015) e009863. https://doi.org/10.1136/bmjopen-2015-009863.

[38] C. Donnelly, S. Quaife, L. Forbes, J. Boylan, C. Tishelman, A. Gavin, Do perceived barriers to clinical presentation affect anticipated time to presenting with cancer symptoms: An ICBP study, Eur. J. Public Health. 27 (2017) 808-813. https://doi.org/10.1093/eurpub/ckx064. 
[39] J.A. Fish, I. Prichard, K. Ettridge, E.A. Grunfeld, C. Wilson, Psychosocial factors that influence men's help-seeking for cancer symptoms: A systematic synthesis of mixed methods research, Psychooncology. 24 (2015) 1222-1232. https://doi.org/10.1002/pon.3912.

[40] Department of Statistics Malaysia, Population and Housing Census of Malaysia: Education and Social Characteristics of the Population 2010, Putrajaya, 2013.

[41] P.N. Kailemia, E.C. Lee, C. Taylor, M.J. Renfrew, Exploring determinants of, and interventions for, delayed presentation of women with breast symptoms: A systematic review, Eur. J. Oncol. Nurs. 44 (2020). https://doi.org/10.1016/j.ejon.2019.101677.

[42] D. Schliemann, M. Donnelly, M. Dahlui, S.Y. Loh, N.S.B. Tamin Ibrahim, S. Somasundaram, C. Donnelly, T.T. Su, The "Be Cancer Alert Campaign": protocol to evaluate a mass media campaign to raise awareness about breast and colorectal cancer in Malaysia., BMC Cancer. 18 (2018) 881. https://doi.org/10.1186/s12885-018-4769-8.

\section{Table legends}

Table 1. Association between sociodemographic and health-care variables and recognition of each cancer warning sign

Table 2. Association between sociodemographic and health-care variables and anticipated delay to help-seeking ( $>2$ weeks) for each cancer warning sign

Table 3. Predictors of help-seeking delay (anticipating $>2$ weeks) for a potential warning sign of cancer $(n=1,836)$

\section{Figure legends}

Figure 1. Symptom recognition and anticipated delay of help-seeking of $>2$ weeks for each related symptom (persistent cough/hoarseness, unexplained bleeding, and unexplained lump or swelling)

\section{Supplementary materials}

Supplementary Table 1. Distribution of participants by state/ territory in Malaysia

Supplementary Table 2. Joint-tested association of associations between delayed help-seeking and variables with more than two categories

Supplementary Table 3. Predictors of help-seeking delay (anticipating $>2$ weeks) for potential warning signs of cancer (unadjusted) 
Table 1. Association between sociodemographic and health-care variables and recognition of each cancer warning sign

\begin{tabular}{|c|c|c|c|c|c|c|c|c|c|c|}
\hline & \multirow{2}{*}{$\begin{array}{c}\text { Total } \\
\mathrm{n}\end{array}$} & \multicolumn{3}{|c|}{ Persistent cough or hoarseness } & \multicolumn{3}{|c|}{ Unexplained bleeding } & \multicolumn{3}{|c|}{ Unexplained lump or swelling } \\
\hline & & $\mathrm{n}$ & $\%$ & p-value & $\mathrm{n}$ & $\%$ & $\mathrm{p}$-value & $\mathrm{n}$ & $\%$ & p-value \\
\hline \multicolumn{11}{|l|}{ Gender } \\
\hline Female & 813 & 456 & 56.1 & 0.578 & 555 & 68.3 & 0.031 & 626 & 77.0 & 0.031 \\
\hline \multicolumn{11}{|l|}{ Age groups } \\
\hline $40-49$ years & 1279 & 702 & 54.9 & & 868 & 67.9 & & 956 & 74.7 & \\
\hline \multicolumn{11}{|l|}{ Ethnicity } \\
\hline Malay & 925 & 541 & 58.5 & & 594 & 64.2 & & 708 & 76.5 & \\
\hline Chinese & 754 & 398 & 52.8 & & 517 & 68.6 & & 552 & 73.2 & \\
\hline Indian & 162 & 84 & 51.9 & & 108 & 66.7 & & 120 & 74.1 & \\
\hline Others $^{\mathrm{a}}$ & 54 & 26 & 48.1 & 0.055 & 23 & 42.6 & 0.001 & 32 & 59.3 & 0.026 \\
\hline Tertiary education & 653 & 353 & 54.1 & $<0.001$ & 447 & 68.5 & $<0.001$ & 511 & 78.3 & $<0.001$ \\
\hline \multicolumn{11}{|l|}{ Marital status } \\
\hline Married & 1663 & 941 & 56.6 & & 1099 & 66.1 & & 1247 & 75.0 & \\
\hline Not married & 231 & 108 & 46.8 & 0.005 & 142 & 61.5 & 0.167 & 165 & 71.4 & 0.245 \\
\hline \multicolumn{11}{|l|}{ Access to doctors } \\
\hline Very easy to somewhat easy & 1814 & 1007 & 55.5 & & 1201 & 66.2 & & 1355 & 74.7 & \\
\hline Very difficult to somewhat difficult & 80 & 41 & 51.2 & 0.453 & 40 & 50 & 0.003 & 56 & 70 & 0.346 \\
\hline
\end{tabular}

${ }^{a}$ Findings from Chi-square test after excluding the 'other' ethnic group: persistent cough or hoarseness $\mathrm{p}=0.040$; unexplained bleeding $\mathrm{p}=0.171$; unexplained lump or swelling $\mathrm{p}=0.282$

Missing variables: Marital status ( $\mathrm{n}=1)$, Access to doctors $(\mathrm{n}=1)$ 
Table 2. Association between sociodemographic and health-care variables and anticipated delay to help-seeking ( $>2$ weeks) for each cancer warning sign

\begin{tabular}{|c|c|c|c|c|c|c|c|c|c|c|}
\hline & \multirow{2}{*}{$\begin{array}{c}\text { Total } \\
\mathrm{n}\end{array}$} & \multicolumn{3}{|c|}{$\begin{array}{l}\text { Persistent cough } \\
(\mathrm{n}=1895)\end{array}$} & \multicolumn{3}{|c|}{$\begin{array}{c}\text { Rectal bleeding } \\
(\mathrm{n}=1895)\end{array}$} & \multicolumn{3}{|c|}{$\begin{array}{c}\text { Breast changes } \\
\quad(\mathrm{n}=813)\end{array}$} \\
\hline & & $\mathrm{n}$ & $\%$ & p-value & $\mathrm{n}$ & $\%$ & $\mathrm{P}$ & $\mathrm{n}$ & $\%$ & p-value \\
\hline All respondents $(\mathrm{n}=1895)$ & & 360 & 19.3 & & 112 & 6.1 & & 20 & 2.5 & \\
\hline \multicolumn{11}{|l|}{ Gender } \\
\hline Male & 1082 & 219 & 20.5 & & 67 & 6.4 & & - & - & \\
\hline Female & 813 & 141 & 17.7 & 0.128 & 45 & 5.8 & 0.598 & 20 & 2.5 & - \\
\hline \multicolumn{11}{|l|}{ Age groups } \\
\hline $40-49$ years & 1279 & 238 & 18.8 & & 70 & 5.6 & & 13 & 2.3 & \\
\hline $50-59$ years & 427 & 88 & 21.0 & & 32 & 7.7 & & 4 & 2.4 & \\
\hline $60+$ years & 189 & 34 & 18.8 & 0.623 & 10 & 5.7 & 0.288 & 3 & 4.9 & 0.459 \\
\hline \multicolumn{11}{|l|}{ Ethnicity } \\
\hline Malay & 925 & 150 & 16.6 & & 71 & 8.0 & & 12 & 3.1 & \\
\hline Chinese & 754 & 174 & 23.3 & & 33 & 4.4 & & 5 & 1.5 & \\
\hline Indian & 162 & 29 & 18.1 & & 4 & 2.5 & & 1 & 1.7 & \\
\hline Others & 54 & 7 & 13.5 & 0.004 & 4 & 7.8 & 0.004 & 2 & 11.1 & 0.054 \\
\hline \multicolumn{11}{|l|}{ Highest level of education } \\
\hline No formal education & 28 & 8 & 33.3 & & 7 & 31.8 & & 3 & 20 & \\
\hline Primary education & 162 & 29 & 18.1 & & 16 & 10.6 & & 1 & 1.4 & \\
\hline Secondary education & 1052 & 211 & 20.4 & & 52 & 5.1 & & 7 & 1.7 & \\
\hline Tertiary education & 653 & 112 & 17.4 & 0.140 & 37 & 5.8 & $<0.001$ & 9 & 3.1 & $<0.001$ \\
\hline \multicolumn{11}{|l|}{ Marital status } \\
\hline Married & 1663 & 311 & 19.0 & & 98 & 6.1 & & 19 & 2.7 & \\
\hline Not married & 231 & 49 & 21.6 & 0.355 & 14 & 6.2 & 0.935 & 1 & 1.2 & 0.430 \\
\hline \multicolumn{11}{|l|}{ Access to doctors } \\
\hline Very easy to somewhat easy & 1814 & 344 & 19.3 & & 99 & 5.6 & & 16 & 2.1 & \\
\hline Very difficult to somewhat difficult & 80 & 16 & 20.5 & 0.782 & 13 & 17.3 & $<0.001$ & 4 & 14.8 & $<0.001$ \\
\hline
\end{tabular}

Missing variables: Anticipated delay to help-seeking for persistent cough $\mathrm{n}=29$, Anticipated delay to help-seeking for rectal bleeding $\mathrm{n}=58$, Anticipated delay to help-seeking for breast changes $n=18$ 
Table 3. Predictors of help-seeking delay (anticipating $>2$ weeks) for a potential warning sign of cancer

\begin{tabular}{|c|c|c|c|c|c|c|c|c|c|c|}
\hline & \multirow{2}{*}{$\begin{array}{c}\text { Total } \\
\\
\mathrm{n} \\
\end{array}$} & \multicolumn{3}{|c|}{$\begin{array}{c}\text { Anticipated delay for } \\
\text { persistent cough }(>\mathbf{2} \text { weeks }) \\
(\mathrm{n}=1864) \\
(19.3 \% \text { anticipated delay })\end{array}$} & \multicolumn{3}{|c|}{$\begin{array}{c}\text { Anticipated delay for rectal } \\
\text { bleeding }(>\mathbf{2} \text { weeks }) \\
(\mathrm{n}=1836) \\
(6.1 \% \text { anticipated delay })\end{array}$} & \multicolumn{3}{|c|}{$\begin{array}{c}\text { Anticipated delay for breast } \\
\text { changes }(>\mathbf{2} \text { weeks }) \\
(\mathrm{n}=795) \\
(2.5 \% \text { anticipated delay })\end{array}$} \\
\hline & & OR & $95 \% \mathrm{CI}$ & $\mathrm{p}$-value & OR & $95 \% \mathrm{CI}$ & $\mathrm{p}$-value & OR & $95 \% \mathrm{CI}$ & $\mathrm{p}$-value \\
\hline \multicolumn{11}{|l|}{ Sex } \\
\hline Male & 1082 & \multicolumn{3}{|c|}{ Reference } & \multicolumn{3}{|c|}{ Reference } & - & - & - \\
\hline Female & 813 & 0.82 & {$[0.65,1.04]$} & 0.104 & 0.90 & {$[0.60,1.34]$} & 0.593 & - & - & - \\
\hline \multicolumn{11}{|l|}{ Age groups } \\
\hline $40-49$ years & 1279 & \multicolumn{3}{|c|}{ Reference } & \multicolumn{3}{|c|}{ Reference } & \multicolumn{3}{|c|}{ Reference } \\
\hline $50-59$ years & 427 & 1.13 & {$[0.85,1.50]$} & 0.395 & 1.30 & {$[0.83,2.05]$} & 0.258 & 0.95 & {$[0.28,3.15]$} & 0.930 \\
\hline $60+$ years & 189 & 0.91 & {$[0.60,1.39]$} & 0.658 & 0.77 & {$[0.37,1.61]$} & 0.483 & 1.07 & {$[0.19,5.97]$} & 0.937 \\
\hline \multicolumn{11}{|l|}{ Marital status } \\
\hline Married & 1663 & \multicolumn{3}{|c|}{ Reference } & \multicolumn{3}{|c|}{ Reference } & \multicolumn{3}{|c|}{ Reference } \\
\hline Not married & 231 & 1.25 & {$[0.88,1.78]$} & 0.219 & 0.99 & {$[0.54,1.83]$} & 0.971 & 0.30 & {$[0.35,2.51]$} & 0.265 \\
\hline \multicolumn{11}{|l|}{ Ethnicity } \\
\hline Malay & 925 & \multicolumn{3}{|c|}{ Reference } & \multicolumn{3}{|c|}{ Reference } & \multicolumn{3}{|c|}{ Reference } \\
\hline Chinese & 754 & 1.58 & {$[1.23,2.03]$} & $<0.001$ & 0.58 & {$[0.37,0.89]$} & 0.014 & 0.65 & {$[0.21,1.95]$} & 0.437 \\
\hline Indian & 162 & 1.16 & {$[0.74,1.80]$} & 0.518 & 0.33 & {$[0.12,0.93]$} & 0.036 & 0.64 & {$[0.08,5.18]$} & 0.673 \\
\hline Others & 54 & 0.71 & {$[0.31,1.62]$} & 0.414 & 0.64 & {$[0.22,1.92]$} & 0.431 & 5.32 & {$[0.99,28.49]$} & 0.051 \\
\hline \multicolumn{11}{|l|}{ Education } \\
\hline No formal education & 28 & 2.64 & {$[1.07,6.54]$} & 0.036 & 5.25 & {$[1.86,14.83]$} & 0.002 & 5.95 & {$[0.86,41.30]$} & 0.071 \\
\hline Primary education & 162 & 1.10 & {$[0.68,1.77]$} & 0.693 & 1.64 & {$[0.84,3.18]$} & 0.144 & 0.32 & {$[0.35,2.80]$} & 0.300 \\
\hline Secondary education & 1052 & 1.26 & {$[0.97,1.63]$} & 0.087 & 0.82 & {$[0.52,1.27]$} & 0.371 & 0.45 & {$[0.16,1.29]$} & 0.139 \\
\hline Tertiary education & 653 & \multicolumn{3}{|c|}{ Reference } & \multicolumn{3}{|c|}{ Reference } & \multicolumn{3}{|c|}{ Reference } \\
\hline \multicolumn{11}{|l|}{ Access to doctor } \\
\hline Very easy to somewhat easy & 1814 & \multicolumn{3}{|c|}{ Reference } & \multicolumn{3}{|c|}{ Reference } & \multicolumn{3}{|c|}{ Reference } \\
\hline $\begin{array}{l}\text { Very difficult to somewhat } \\
\text { difficult }\end{array}$ & 80 & 1.20 & {$[0.67,2.14]$} & 0.532 & 2.37 & {$[1.21,4.66]$} & 0.012 & 7.58 & {$[1.98,28.94]$} & 0.003 \\
\hline \multicolumn{11}{|l|}{$\begin{array}{l}\text { Do you think this is a } \\
\text { symptom of cancer? }\end{array}$} \\
\hline No & & 1.10 & {$[0.87,1.39]$} & 0.415 & 1.54 & {$[1.03,2.31]$} & 0.036 & 0.41 & {$[0.09,1.81]$} & 0.241 \\
\hline Yes & & \multicolumn{3}{|c|}{ Reference } & \multicolumn{3}{|c|}{ Reference } & & Reference & \\
\hline
\end{tabular}

OR - odds ratio; CI - confidence interval

The odds ratios in the model were adjusted for sex, age groups, marital status, ethnicity, education, access to doctor and cancer symptom awareness. 